\title{
A Cognitive Study of Double-object Constructions in English and Chinese
}

\author{
Yuanmei Li \\ School of Foreign Languages, Guizhou Normal University, Guizhou, China
}

\begin{abstract}
Double-object is a kind of syntactic structure which is common in English and Chinese. In the field of linguistics in China, the similarities and differences between English and Chinese double-object sentences have been discussed and debated. Based on the perspective of cognitive linguistics, this paper probes into the metaphor cognition, metonymy cognition and both of them in the double-object constructions of English and Chinese, and points out that the double-object constructions in English and Chinese are similar in the above three aspects. However, there are also differences between English and Chinese double-object constructions, which are manifested in the following three aspects: the scope of double-object constructions, the conceptual patterns and the verbs that can enter the double-object constructions. By analyzing the similarities and differences between English and Chinese double-object constructions, it can be concluded that the syntactic structure of English and Chinese objects reflects the conceptual structures of human beings and the ways of cognition of the world, and even the sentence structure containing the same conceptual content will lead to the difference in meaning because of the different cognitive styles of events.
\end{abstract}

Index Terms - cognition, construction grammar, double object constructions, contrastive analysis

\section{INTRODUCTION}

Double-object structure is widely used in English and Chinese. It has always been a research topic of great interest and importance to scholars at home and abroad. It is well known that one of the basic word orders of English and Chinese sentences is SVO, and the abstract form of their double-object structure is $\mathrm{S}+\mathrm{V}+\mathrm{N} 1+\mathrm{N} 2$, where N1 represents the indirect object and $\mathrm{N} 2$ represents the direct object.

The researches on double-object structures by scholars at home and abroad are mostly carried out within the framework of traditional grammar or based on the theories of structuralist linguistics and valence grammar. In recent years, construction grammar, which belongs to cognitive linguistics, has provided a new perspective for the study of double-object. Goldberg (1995), the main representative of construction grammar, used construction theory to discuss the characteristics of English double-object constructions in detail. He argues that the archetypal semantics of English double-object statements are "the agent consciously and successfully imparts the object to the recipient," by means of metaphor and metonymy, other similar semantics are derived, that is, the "giving" of the actor. In addition, Goldberg also explains that some divalent verbs that do not have the meaning of "giving" can enter the double-object constructions.

In China, many scholars have also begun to use construction grammar to explore and study the differences between English and Chinese double-object sentences. He Xiaowei (2003) and Wang Yin (2006) discussed the grammaticalization process of VNN constructs based on the hypothesis of "the interaction between nouns and verbs", and obtained the commonly distinguished double-object structures and the object complement structures. These can all be regarded as the unified syntactic phenomena attributed to VNN construction blocks, all of which are restricted by the meaning of VNN construction blocks. Zhang Bojiang (1999) introduced the Goldberg construction grammar theory into the study of double-object in Chinese, and divided the double-object verbs into 13 categories, such as "verbs which have the meaning of giving" and "verbs which have the meaning of acquiring.", which laid a foundation for us to contrast the double-object in Chinese and English. Zhang Jianli (2006) conducted a synchronic and diachronic investigation of English and Chinese double-object sentences by using construction grammar and based on the usage model, and concluded that English double-object constructions have the sense of "giving", while Chinese double-object constructions lead to two inherited constructions, with the meanings of "giving" and "acquiring" respectively. In addition, Xiong Xueliang (2007) discusses the cognitive framework activated by the use of double-object structures, the distribution of components in the framework, the prototype of double-object structures and the relationship between the high-prototype and the low-prototype double-object structures. To sum up, previous researchers have conducted a lot of theoretical analysis and discussion on double-object constructions from multiple perspectives, but the depth and breadth of relevant studies are not enough to further explore the underlying causes of such differences, and there exist differences on some major issues. On the basis of the existing researches, this paper will critically absorb and draw on the existing researches on English and Chinese in accordance with the principles of cognitive construction grammar, and continue the cognitive research on English and Chinese double-object constructions. This paper takes the differences between English and Chinese verbs with double-object as the starting point, makes a deep cognitive analysis 
of English and Chinese double-object constructions, and explains the differences between them and the root causes from the perspective of macro language system.

\section{TERMINOLOGY}

In this paper, it is established that construction, valence and structure are three related conceptual entities at different levels of analysis. In other words, a sentence can be analyzed differently at different levels of analysis. Based on this, this part will define and distinguish the three terms involved.

Construction is a "combination of form and meaning" or "combination of form and function". That is, whether simple or complex constructions have their own independent forms, semantics, and functions. Construction grammar is a theoretical system based on cognitive linguistics, and there is an inherent regularity in the form and meaning of the structure. A construction is a complete cognitive schema, a Gestalt, the whole is greater than the sum of parts. The whole meaning is not equal to the simple addition of each component. In other words, the meaning of the whole cannot be separated from the partial meaning, but it cannot be derived entirely from the partial meaning. In short, the meaning of a sentence $=$ construction meaning + lexical meaning. Among them, the overall meaning of construction and the meaning of lexical components are an interactive relationship. Typical lexical semantics create an inside-out pressure on the formation of sentence semantics, which forces the word to undergo some changes in meaning and function, and enters the sentence structure through the extended mechanism of metaphor or metonymy.

The valence is related to the verb entering the double-object construction, which refers to the dominant power of the verb over the subordinate components of the verb. This ability reflects the semantic nature of the verb and determines the argument structure formed by the verb and the argument category in the structure. Therefore, valence describes the potential ability of the verb as a lexical item before it enters the sentence. For example, in the argument structure of the verb "give", there are three dominant arguments, the agent (the intentional initiator of the action), the concern (the non-active participant of the action) and the acceptor (the stressed object of the action). Therefore, the verb "give" is called a trivalent verb or a ditransitive verb. The verb "knit", by contrast, is a divalent or unitransitive verb, because it involves only two governed arguments: the act of giving and the act of receiving.

Different from construction, structure refers to the type of surface syntactic structure. For instance, "He gave me a book." This is a double-object statement because the verb "give" is followed by two objects, abstracted as structured as $\mathrm{S}+\mathrm{V}+\mathrm{N} 1+\mathrm{N} 2$, it can be seen from this that the intrinsic valence of a verb and the structure it can enter are obviously at two different levels of analysis, the former reflecting the syntactical relations between a verb and other verbs, and the latter reflecting the specific syntactical relations of the verb. That is to say, the valence of a verb is certain, but because the verb can enter into more than one structure, the element in the specific structure does not necessarily match its valence. For example, the verb "give" can also enter the mono-object structure, in the sentence--- "he gave a book" , it has only two arguments.

\section{Cognitive ANALYSIS OF ENGLish AND CHINESE DOC}

The syntactic form of English and Chinese double-object constructions is $\mathrm{S}+\mathrm{V}+\mathrm{N} 1+\mathrm{N} 2$. Its functional or constructive meaning can be described as: "the agent conducts a directed transfer to the subject, which relates to and affects the matter involved". In this part, a further cognitive analysis of English and Chinese double object constructions will be made.

\section{A. Types of Double-object Verbs in English and Chinese}

The constructional meaning has certain restrictions on the types of verb entering the double-object structures, and not all verbs can enter the double-object structures. As for the verbs entering the double-object structures, different scholars have different classification, and $\mathrm{Xu}$ Shengheng divides the verbs into three categories: the first kind of verbs have the meaning of "giving"; the second kind of verbs have no obvious "giving" meaning, but this meaning is latent; the third kind of verbs do not have the meaning of "giving". On this basis, this paper will add the fourth kind of verbs with the meaning of "acquiring", and discuss and explain the four kinds of verbs.

\section{Verbs that have the meaning of "giving"}

These verbs have a clear semantic direction and purpose, and syntactical realization of this semantic meaning through the dual transitive sentence form. Such verbs themselves have the explicitly "giving" meaning and appear in VNN construction blocks, which reinforce each other with the meaning of VNN construction blocks.

In English, these verbs mainly include: give, lend, bring, deliver, rent, offer, pay, pass, hand, throw, etc.. For instance,

a) John gave Mary the book.

b) They offered John a job.

In Chinese, these verbs mainly include: 给, 送, 奖励, 支援, 还, 交, 退, 补, 寄 and so on. For example,

b) 我过三五天准还你钱。

d）老洪给了他一支笔。

2. Verbs that have no obvious "giving" meaning

This kind of verbs are mainly used in the process of interpersonal communication and interaction. There is no 
obvious sense of "giving", but the result is consistent with the meaning of construction mainly through the way of verb expansion.

Their VNN construct blocks imply that the agent transfers the object (N2) to the acceptor (N1) by unfolding the action of V. The verb "teach", for example, is the ultimate transfer of knowledge (N2) to the recipient (N1) by teaching. The way these verbs unfold is a typical extension of the "giving" meaning through the hand. From the perspective of the semantic space involved in the action, there must be two transitive objects, so that the action process is complete and reasonable.

The most common verbs in English are: teach, ask, improve, tell, slow, guarantee, show, permit, improve, etc. For example,

a) I always tell my daughter a story before she goes to sleep.

b) He teaches the boys history.

The most common verbs in Chinese are: 教, 问, 告诉, 嘱咐, 回答, 答复 and so on. For instance,

c) 赵老师教我数学。

d）李明告诉我他的秘密。

\section{Verbs that have no "giving" meaning}

This kind of verb mainly means to produce the service meaning without the "giving" meaning itself, and the semantic space formed by the verb does not necessarily require two transitive objects to appear at the same time, but when one transitive object N2 appears, another transitive object N1 may exist potentially.

When these verbs enter the VNN construction block, N1 actually appears, and the latent giving meaning becomes the implied meaning of the actual existence. Just look at the example, "knit a sweater", the action of knitting potentially has the recipient of the sweater.

Common verbs in English are: draw, sing, cook, make, bake, find, pour, point, knit, etc.. For example,

a) Could you draw me a picture?

b) I'll knit him a sweater.

The Chinese verbs corresponding to these verbs in English are greatly restricted and generally cannot enter the VNN construction block. Instead, the preposition "给" is often used to elicit the recipient before the predicate. For instance,

c) 我给你编一支花篮。

d) 他给我唱了一首歌。

\section{Verbs that have the meaning of "acquiring"}

After these verbs that have the meaning of "acquiring" in English entering into the double-object construction block, the constructional meaning suppresses the lexical meaning, indicating that the subject transfers the object to the recipient, while the Chinese verbs that have the meaning of "acquiring" retains the semantic meaning of such a verb and the subject becomes the recipient.

In English, these verbs are: buy, take, grab, win, earn, etc.. For instance,

a) John bought Mary a dress.

b) John took Mary a book.

In Chinese, these verbs are: 偷, 拿, 买 and so on. For example,

c) 他偷了小王一本书。

d) 他拿了我的一支铅笔。

\section{B. Cognitive Analysis of English Double-object Construction}

According to Goldberg's construction grammar, the English double-object construction refers to the event that the subject affects the indirect object in some way by making it accept the direct object. In this case, the subject acts consciously, the action is a transitive act, and the indirect object is the willing recipient.

In the process of using language, the connection of "subject", "recipient" and "object" constitutes the double-object construction, so it is easy to co-exist with the verb "give", because in the process of conceptualization and language use, the concept of "giving" is influenced by the isomorphism of language and world, which stipulates that the verb has a syntactic relationship with two objects and produces double-object structure. At the same time, because verbs that have the meaning of "giving" are used repeatedly in the structure, the meaning of "giving" is solidified into the double-object construction, which makes the sentence get the meaning of "giving ". Therefore, in the English double-object construction, verbs that have the meaning of "giving" are the high-prototype double-object constructions. If there are verbs that have no meaning of "giving" and non-trivalent verbs in the double-object constructions, but these verbs can be explained with the meaning of "giving" or trivalent explanations, the sentence pattern has a constructional effect, thus producing a low-prototype double-object constructions. For example,

a) knit him a sweater; b) pour me a drink;

c) sing them a song; d) bake him a cake.

It seems that there is no systematic connection between these verbs, but if they are analyzed in the double-object constructions, it can be found that the original intention and the possible result of the action expressed by the non-" giving " meaning verbs and the non-trivalent verbs are embodied in this construction as a sentence pattern that can 
symbolize the process or event of "transferring", and the result is implicitly given to the recipient or indirect object.

If there is a non- "giving" meaning verb in English double-object construction, the syntactic structure will temporarily change the meaning of the verb, assign the verb the meaning of "giving" or project the usage of "giving ", and the non-trivalent verb will change the usage of the verb if it has a trivalent effect in the double-object construction, but the result will be a low-prototype double-object construction. For example, in the case of "sing them a song", "them" is not a subject of "sing", so there is no semantic domination relationship between them. But in the double-object sentence, "them" becomes a necessary part of the sentence, and its function is assigned by the sentence, which interacts with the verb to produce the construction meaning to be expressed. That is to say, the indirect object does not necessarily have a semantic relationship with the verb directly, but participates in role reassigned or supplemented in the cognitive framework activated by the double-object construction.

In English double-object construction, there is a radial systematic inheritance relationship between the sentence forms of high and low prototypes: the emergence of the verb that have the meaning of "giving" or the structure of the argument containing three arguments is the prototype of the double-object construction; Non-trivalent and non-"giving" meaning verbs derive the meaning of "giving" from sentence structure, which are the subclasses derived from the extension and system inheritance of the high-level double-object construction.

\section{Cognitive Analysis of Chinese Double-object Construction}

The semantic meaning of Chinese double-object construction is "giving", it means that the agent acts consciously, and the action is a kind of efferent behavior, which involves the recipient and gains the benefit, for example, "I paid him 20 dollars". However, in addition to the form of "giving" construction, there exists the form of "acquiring" meaning: the agent acts consciously, and the action is an act that introduces the subject to the object and causes the loss of the object involved. For instance, "he stole some books from me". In terms of the profit and loss of the main argument of the two constructions, the agent in the former construction is impaired and the recipient involved is beneficial. On the contrary, in the latter construction, the agent benefits while the recipient involved is impaired, and the two constructs form a reverse contrast.

However, there is also a correlation between the two constructs because the meaning of "giving" and the meaning of "acquiring" are closely related, and the Chinese double object construction has an epistatic structure: object ownership transfer, and the cognitive diagram is "agent makes the object transfer to the reference object ". The epistatic structure and its sub-structure form the relationship between model and instance, which can be summed up to form the continuum of object ownership transfer. Moreover, the form of the construction adds to the valence of the verbs entering the construction, and the involvement is usually increased. For example, "He stole some books from me." The verb "steal" should have not only content but also object to fill the two object spaces. Furthermore, the function of the construction will suppress and modify the meaning of the verbs into the construction.

The double-object structure of Chinese has two opposite semantic constructs, so the concrete structure type into the structure of the verb depends on the transfer direction meaning of the verb: "impaired" or "beneficial", and those verbs with unclear meaning of transfer direction is on the edge of the border of the two constructs. Therefore, the Chinese constructions match the lexical meanings of verbs.

\section{The Similarities And DifFerences Between English and Chinese Double-OBJeCt CONSTRUCTIONS}

The similarities and differences between English and Chinese double-object constructions are a controversial topic in the field of linguistics in China. By comparing English and Chinese, it can be found that English and Chinese double-object sentences are not completely equivalent, and there are many similarities and differences between them.

\section{A. The Similarities of Double-object Constructions in English and Chinese}

As mentioned above, both the English and Chinese double-object constructions are $\mathrm{S}+\mathrm{V}+\mathrm{N} 1+\mathrm{N} 2$, and their prototype meaning is: $\mathrm{X}$ causes $\mathrm{Y}$ to receive $\mathrm{Z}$. In addition to this prototype meaning, the construction also derives many other non-central usages, that is, it has semantic polyseness like vocabulary. In fact, the reason for this polysemy comes from the extension mechanism such as metaphor or metonymy. Metaphor and metonymy are ubiquitous in our daily life and affect our thoughts and actions. The creativity of language lies in embedding concrete words into the sentence structure through the extension mechanism such as metaphor or metonymy. Common cognitive experience makes English and Chinese have the same extension mechanism.

\section{The cognitive pattern of metaphor}

Metaphor involves two cognitive domains, mapping structures or relationships in one cognitive domain to another. Generally speaking, it extends from a concrete, realistic, more familiar field to another abstract, unfamiliar one.

The basis of metaphor is the synthetic similarity between the two things. The similarity between two recognizing domains refers to the similarity characteristics between the source domain and the target domain. In fact, the typical object structure of English and Chinese is the tangible entity of material space, but under the cognitive mode of metaphor, the entity of material space is mapped to the field of immaterial space or discourse space. Please look at these examples,

a) She owes me a grudge. 
b) 他给了我一些建议。

“grudge” 和 “建议” are respectively mapped from the specific physical domain to the non-physical space domain or the discourse space domain. The synthetic similarity is "can be endowed with "giving" meaning and transferred. Similar examples are: “The patient gave Tom a headache”. “他给了我一些建议” and so on.

\section{The cognitive pattern of metonymy}

Metonymy involves the relationship between prominence and proximity. An object or a concept will have many attributes, while human cognition tends to pay more attention to its most prominent attributes, which is the prominence attribute. Metonymy refers to the use of one salient object to refer to or replace another in the same domain, such as referring to the whole by the part and to its function or content by the container.

Under the function of metonymy, the indirect object and direct object in the constructions of English and Chinese double-object sentences may be replaced by abstract things, and their relationship with the abstract things is just like the relationship between the part and the whole. There are some examples,

a) Jimmy sent Chicago a letter.

b) I pretend to give him the cold shoulder.

c) 大嫂子顺手给了他一巴掌。

d) 晓荷送给太太一个媚眼。

In example a), the word Chicago is used to replace someone who lives in Chicago. The second sentence can be translated into Chinese: “我故意冷落他”. The verb phrasal “the cold shoulder” is used to replace the event that I ignored him. In the same way, the rest of the two Chinese sentences can be analyzed from the perspective of metonymy. "一巴掌" and "一个媚眼" represent incidents of beating someone and insinuating someone respectively.

\section{The cognitive pattern of metaphor and metonymy}

In the extension of double object constructions, metaphor and metonymy do not exclude each other, by contrast, they are an organic continuum that is interrelated and complementary. For example: "单位照顾我一套房子."

In this sentence, the agent is extended from "person" to "place", which is the result of the combination of metaphor and metonymy cognitive model. People and the place where he or she works are cognitively related, there is a relationship between the part and the whole, thus the place where people works can be used to refer to the people. This is metonymy. Therefore, it can be seen that under the combination of metonymy and metaphor, the place where people woks has some characteristics of human beings and can assume the role of agent.

All in all, the polysemous phenomenon of double object construction is the process of extending from a central meaning or typical meaning to a non-centrical meaning or other meaning through human cognitive means, and it is the result of the category and conceptualization of human cognition. The cognitive patterns of metaphor and metonymy are based on people's basic experience, and they are ubiquitous in human daily life, which affects human thoughts and behavior. As Wang Yin said, the meaning of grammatical construction must be explained by the prototype category, cognitive model, image schema, mental fusion, metaphor mechanism and so on advocated by cognitive linguistics.

\section{B. The Differences of Double-object Constructions in English and Chinese}

Each language embodies the nation's own thinking characteristics, Chinese follows savvy thinking, English follows rational thinking. Chinese is often based not on rigorous formal analysis but on savvy thinking to get the relationship. The most prominent feature of sentence construction in Chinese is that Chinese put emphasis on parataxis, it means Chinese emphasize meaning combination rather than formal structure. On the contrary, English sentences mainly use hypotaxis, emphasize form structure coordination, and show meaning by form. There are also many asymmetries in the extension of the double-object construction in English and Chinese.

\section{The different constructions ranges}

There are two main differences in the range of double-object constructions between English and Chinese. As mentioned above, Chinese double-object sentences are semantically divided into two categories: "giving" meaning and "acquiring" meaning. In Chinese double-object constructions, there is a semantic relative relationship between some "giving" verbs and "acquiring" verbs.

The two kinds of double-object sentences which are composed of these verbs can show us the semantic contrast between them. However, there is no such contrast in English double-object sentences, because English double-object sentences do not have the same "acquiring" verbs as Chinese. No matter whether the verb in the sentence is the "giving" meaning or "acquiring" meaning, the whole double-object sentence pattern expresses the same semantic meaning, that is: $\mathrm{X}$ causes $\mathrm{Y}$ to receive $\mathrm{Z}$. For instance, He is going to sell me an old car. (他准备卖给我一辆旧车。) He is going to buy me an old car. (他准备买一辆旧车给我。) He gave me a ticket. (他给了我一张票) He got me a ticket. (他 弄了一张票给我。) From these examples, it can be seen that when the verb in the sentence is the "acquiring" meaning verb, although the sentence pattern of English and Chinese double-object sentences are exactly the same, the semantic is completely opposite.

Secondly, there exists double-object structure with some predicative-object verbs in Chinese. In Chinese, the predicative-object verbs can take double objects, but there is no such phenomenon in English. A predicative-object verb is a compound verb with a dominant and dominated relationship between morphemes, such as " 放心, 出口 ", etc. But 
there is no such phenomenon in English, which is because there is no such grammatical structure within the corresponding words in English. In Chinese, it is not particularly common for the predicative-object verb to be able to carry double-object, because the predicative-object verb has already had an object-like component inside the word-formation, the transitivity of the whole verb is affected, so the predicative-object verb which can take objects has a small proportion of all the predicative-object verbs. What's more, the double-object structure requires the verb not only to have an object, but also two objects, so the number of predicate-object verbs that can meet this requirement is relatively small. At the same time, the structure of the verb with double-object also has its characteristics, that is, the direct object before the general Chinese has a unique quantifier modification.

\section{The different conceptual patterns}

The concept of object in Chinese is different from that in English. There are locative objects in Chinese, such as “擦 黑板, 住旅馆, 骂街 and so on. As a result, there is a unique double-object structure in Chinese, which is composed of locative objects and target objects. There are some examples,

a) 他偷了小王一辆自行车。( He stole a bicycle from Xiao Wang.)

b) 他拿了我一本书。( He took a book from me.)

c) 他买了王教授一本书。( He bought a book by Professor Wang.)

d) 我娶了他一个女儿。( I married one of his daughters from him.)

In these sentences, Xiao Wang, me, Professor Wang, him are not target objects, they are locative objects. The real target objects are bicycle, book, one of his daughters. The decisive feature of this structure is the transfer of ownership.

In addition, the indirect object is allowed to shift to the left in the Chinese specific double-object structure. Langaker believes that the grammatical meaning of the English double-object form is the "source-target path ", that is, the object can only shift from the subject direction to the right. It should be noted, however, that in this structure, which consists of the resulting verbs and the escape verbs which themselves have no transfer significance, the object moves directly to the right. In the special structure of "locative objects + target objects" in Chinese, the object does not transfer from the subject to the indirect object, that is, not to the right, but to the subject, that is, to the left. In Chinese double-object structure, the object can be transferred to the right or left. In English double-object structure, the object is transferred to the right, that is, the subject is transferred to the indirect object.

\section{The different verbs}

Chinese double-object sentences are semantically divided into two categories: "giving" meaning and "acquiring" meaning. Some semantic verbs of "giving" meaning and "acquiring" meaning have a semantic relative relationship, and the two kinds of double-object sentences composed of them can show the obvious semantic opposition between "giving" meaning and "acquiring" meaning.

Since the Chinese double-object sentence patterns can express the two opposite semantics of "giving" meaning and "acquiring" meaning according to the semantic meaning of verbs, then the double-object statements composed of the verb with the two semantics of "giving" meaning and "acquiring" meaning will have the imagination of homomorphic heterosemous meaning, and its exact semantics need to be determined by the specific context to exclude ambiguity.

However, English double-object sentences only express the meaning of "giving", so English double-object sentences have a restrictive effect on verbs with two semantic meanings of "giving" and "acquiring". As long as verbs with two semantic meanings of "giving" and "acquiring" enter the double-object sentence pattern, they can only show the semantic meaning of "giving".

Because of the difference of grammatical kinetic energy of verbs, the following verbs can carry double-objects in English, but not in Chinese. Verbs that convey information in language: "read, tell, write, sing, recommend" in English; “读、念、写、唱、推荐” in Chinese. Verbs for transporting: “bring, fetch, take, mail, remit” in English; “带、拿、捎、 邮、汇” in Chinese. Verbs that have the meaning of "giving” : "offer, afford, awarded, allocated, bequeath, leave" in English; “提供、遗留、留下、判” in Chinese.

Result objects exist in both English and Chinese languages. The result objects do not exist before the action, instead it is the result of the action, such as "make a dress". The dress does not exist before the action make. It is the result of making. In English, a result verb can be followed by the "indirect object + direct object" structure. For instance, "She made her daughter a new dress". However, Chinese result verbs cannot be followed by the "indirect object + direct object" structure.

\section{CONCLUSION}

Based on the perspective of cognitive linguistics, this paper probes into the metaphor cognition, metonymy cognition and both of them in the double-object constructions of English and Chinese, and points out that the double-object constructions in English and Chinese are similar in the above three aspects. However, there are also differences between English and Chinese double-object constructions, which are manifested in the following three aspects: the scope of double object constructions, the conceptual pattern and the verbs that can enter the double object constructions.

By analyzing the similarities and differences between English and Chinese double-object structures, it can be concluded that the syntactic structure of English and Chinese objects reflects the conceptual structure of human beings and the way of cognition of the world, and even the sentence structure containing the same conceptual content will lead 
to the difference in meaning because of the different cognitive styles of events. The commonness of English and Chinese double-object constructions reflect the same way of cognition of different peoples to the world, and the difference of English and Chinese double-object constructions reflect the different cognition and sentence meaning of English and Chinese.

\section{REFERENCES}

[1] Bojiang Zhang. (1999). The Double Transitive Structure Formula of Modern Chinese. Chinese Language, (3): 175-184.

[2] Croft, W. \& D. A. Cruse. (2004). Cognitive Linguistics. Cambridge: Cambridge University Press.

[3] Goldberg, A. E. (1995). Constructions: A Construction Grammar Approach to Argument Structure. Chicago: University of Chicago Press.

[4] Goldberg, A. E. (2003). Constructions: A new theoretical approach to language. Journal of Foreign Languages, (3):1-11.

[5] Jianhua Hu. (2007). Theta-Roles, Arguments, and GF-Case-marking Effect and Language Variation. Foreign Language Teaching and Research, (3): 163-168.

[6] Jianli Zhang. (2006). Toward a Cognitive Study on Double-Object Sentences in English and Chinese. Journal of Foreign Languages, (6): 15-21.

[7] Malchukov A. L. (2007). Animacy and asymmetries in different case making. Lingua-1322.

[8] Qilong Cheng. (2004). Ditransitive Construction and Its Related Conceptual Network. Journal of Foreign Languages, (3): 20-25.

[9] Qiyang Mo, Xu Wen. (2007). A Cognitive-Linguistic Approach to the English DOC and DC Constructions. Foreign Language Education, (4): 6-11.

[10] Xiaowei He. (2003). The Relationship between the Double Object Construction and the Dative Construction. Journal of Foreign Languages, (2): 25-31.

[11] Xueliang Xiong. (2007). An Analysis of the Prototypicality of Ditransitive Constructions in English and Chinese. Foreign Language Teaching and Research, (4): 261-267.

[12] Yanping Dong, Junying Liang. (2002). A Constructional Approach to Grammar. Modern Foreign Languages, 25 (2): $142-152$.

[13] Yin Wang. (2006). An Introduction to Cognitive Grammar. Shanghai: Shanghai Foreign Language Education Press.

[14] Yuzhi Shi. (2004). The Motivation of Conceptualization for the Difference of Double Object Construction between Chinese and English. Foreign Language Teaching and Research, 36(2): 83-89.

Yuanmei Li was born in Guizhou, China in 1996. She is currently a postgraduate student working on master degree in the School of Foreign Languages, Guizhou Normal University, Guizhou, China. Her research interests include cognitive linguistics and pragmatics 